\title{
Design and Evaluation of a Self-Emulsifying Drug Delivery System of Aripiprazole
}

\author{
A. R. RAMYA, PREETHI SUDHEER* A. S. MOHAMEID ${ }^{1}$ AND A. K. DAS ${ }^{2}$ \\ Department of Pharmaceutics, Krupanidhi College of Pharmacy, Chikkabellandur, Carmelaram Post, Varthur, Hobli, Bangalore \\ -560 035, India, ${ }^{1}$ Department of Pharmaceutics, Faculty of Pharmacy, Omar Al-Mukhtar University, Libya, ${ }^{2}$ Department of \\ Chemistry, Krupanidhi College of Pharmacy, Chikkabellandur, Carmelaram Post, Varthur, Hobli, Bangalore-560 035, India
}

\section{Ramya et al.: Design and Evaluation of Self-emulsifying Drug Delivery System}

\begin{abstract}
The present investigation is aimed at enhancing the solubility and the dissolution rate of aripiprazole by formulating a self-micro emulsifying drug delivery system. The preliminary solubility screening of aripiprazole was determined in oils, surfactants and cosurfactants, respectively. Among those screened, isopropyl myristate, Tween 80 and propylene glycol showed good solubilizing efficiency and were selected for further formulations. A pseudoternary phase diagram was constructed at the ratios of 2:1, 3:1, 4:1 of oil to $S_{\text {mix }}$ (surfactant:Tween 80) and cosurfactant (propylene glycol) to find out the self-emulsification region. In vitro dissolution studies of the formulations were carried out in a simulated acidic buffer $\mathrm{pH}$ 2.2. A liquid self-micro emulsifying drug delivery system with an optimum composition was converted to solid formulation using crospovidone. Both solid and liquid formulations were evaluated for the cloud point and self-emulsification time. Differential scanning calorimetry endotherm provided confirmation for the amorphisation of the drug. Zeta potential and particle size analysis was carried out on the optimized formula. These studies revealed that the prepared self-micro emulsifying drug delivery system exhibited increased dissolution rate profile in comparison to the pure drug and marketed aripiprazole tablets.
\end{abstract}

Key words: Isopropyl myristate, Tween 80, propylene glycol, aripiprazole, SMEDDS

With the advent of advanced drug discovery techniques, the process of identification of complex chemical compounds having excellent therapeutic potential has improved leaps and bounds. However, poor drug solubility translates to low systemic bioavailability which necessitates the use of a higher dose, where a large portion of the dose is not utilized ${ }^{[1]}$. Drugs that belong to the biopharmaceutics classification system (BCS) class IV exhibit low oral bioavailability, which is attributed to poor solubility and low permeability ${ }^{[2]}$. Aripiprazole, a BCS class IV drug is an atypical antipsychotic agent that acts as a partial agonist at the dopamine $\left(\mathrm{D}_{2}\right)$ receptors and as an antagonist at the serotonin (5-HT2A) receptors. Antipsychotic drugs tend to block dopamine $\mathrm{D}_{2}$ receptors in the dopaminergic pathways of the brain. It is well absorbed orally, undergoes extensive extravascular distribution, metabolized by CYP3A4 and CYP2D6 isozymes. The drug has an oral bioavailability of only $60-70 \%{ }^{[3-6]}$.

A lot of research has been aimed at improving the bioavailability of these class of drugs. Self-micro

*Address for correspondence

E-mail: preetisudheer@gmail.com

November-December 2019 emulsifying drug delivery systems (SMEDDS) are mixtures of oils, co-solvents and surfactants, which are isotropic in nature and these emulsify spontaneously to produce fine oil-in-water emulsions when introduced into an aqueous phase under gentle agitation. After oral administration, these systems form fine emulsions (or microemulsions) in the gastro-intestinal tract (GIT) with mild agitation due to gastric mobility. These systems have a droplet size between 10-200 nm, which accounts for a high degree of transparency than those of a conventional emulsion (has a droplet size between 1-20 $\mu \mathrm{m}$ ). These stable preparations improve the dissolution of the drug due to the increased surface area on dispersion and the solubility effect of surfactants ${ }^{[7-9]}$. In the current investigation a SMEDDS of aripiprazole

This is an open access article distributed under the terms of the Creative Commons Attribution-NonCommercial-ShareAlike 3.0 License, which allows others to remix, tweak, and build upon the work non-commercially, as long as the author is credited and the new creations are licensed under the identical terms

Accepted 18 October 2019

Revised 21 July 2019

Received 14 May 2019

Indian J Pharm Sci 2019;81(6):1089-1098 
is attempted to increase its solubility. This approach also increases the dissolution rate and permeability of aripiprazole, thus the oral bioavailability of the drug could be improved.

\section{MATERIALS AND METHODS}

Aripiprazole was a gift sample from Watson India Ltd., Mumbai, India. Isopropyl myristate (IPM), Tween 80, propylene glycol, crospovidone was procured from S. D. Fine Chemicals, Mumbai, India. Double-distilled water was used throughout the experiment.

\section{Drug excipient compatibility studies:}

A Fourier-transform infrared spectrum (FTIR) was used to identify if any interaction existed between aripiprazole and the excipients used. The samples were analysed via potassium bromide pellet method in an IR spectrophotometer (Thermo-Nicolet 6700) in the region $4000-400 \mathrm{~cm}^{-1}$. The resolution set for the FTIR analysis was $4 \mathrm{~cm}^{-1}$.

\section{Excipient screening, saturation solubility studies:}

The solubility of aripiprazole in various oils, surfactants and co-surfactants was determined by dissolving an excess amount of aripiprazole in $2 \mathrm{ml}$ of each of the selected oils, surfactants and cosurfactants in $5 \mathrm{ml}$ stoppered vials separately and the contents of the vials was shaken on a vortex mixer at $37^{\circ} \pm 1^{\circ}$ for $72 \mathrm{~h}$ to reach equilibrium. The vials were then centrifuged at $3000 \mathrm{rpm}$ for $15 \mathrm{~min}$. The supernatants were separated by filtering through a membrane. Aliquots of the supernatant were diluted with methanol and the aripiprazole content was determined on a UV spectrometer at a $\lambda_{\max }$ of $255 \mathrm{~nm}$. The surfactant and cosurfactant, which showed maximum solubility for aripiprazole was selected for formulation $^{[10]}$.

\section{Development of pseudoternary phase diagram:}

Pseudoternary phase diagrams were designed via the PROSIM ternary diagram software. In order to construct the phase diagram, 5 different surfactant to cosurfactant (Tween 80 to propylene glycol) ratios were studied; i.e. 1:1, 2:1, 3:1, 4:1 and 5:1. These mixtures (S/Cos) were mixed with the oil phase to give the weight ratios of $9: 1,8: 2,7: 3,6: 4,5: 5,4: 6,3: 7,2: 8$ and $1: 9$. These mixtures were subsequently mixed thoroughly on a magnetic stirrer and were titrated against distilled water till the system turned cloudy. The tendency to emulsify spontaneously was also observed ${ }^{[11]}$.

\section{Preparation and evaluation of liquid SMEDDS formulation:}

The formulations were prepared by dissolving aripiprazole in the mixture of surfactant, co surfactant and oil. A clear solution was obtained on vortexing the final mixture ${ }^{[12]}$. SMEDDS preparation $(1 \mathrm{~g})$ was diluted 1:10 and 1:250 with distilled water and $0.1 \mathrm{~N}$ $\mathrm{HCl}$, respectively and the percent transmittance was measured at 450 and $600 \mathrm{~nm}^{[13]}$.

Excess amount of aripiprazole was added to blank formulations in $5 \mathrm{ml}$ stopper vials. The liquids were mixed by vortexing at $37 \pm 1^{\circ}$ for $72 \mathrm{~h}$ to reach equilibrium. The equilibrated samples were centrifuged at $3000 \mathrm{rpm}$ for $15 \mathrm{~min}$. The supernatant was collected and filtered through a membrane filter. Aliquots of the supernatant were diluted with methanol and the drug content was quantified on a UV spectrometer at $\lambda_{\max }$ $255 \mathrm{~nm}^{[13]}$.

The self-emulsification of SMEEDS formulation was determined by adding $1 \mathrm{~g}$ of SMEEDS preparation into $250 \mathrm{ml}$ of distilled water, this mixture was magnetically stirred at $50 \mathrm{rpm}^{[14]}$. In cloud point determination study, the formulation was added to $250 \mathrm{ml}$ of distilled water and heated until it turned turbid. As the body temperature is $37^{\circ}$, formulations should exhibit a cloud point higher than body temperature to retain selfemulsification property ${ }^{[14]}$.

Drug release from liquid SMEDDS was measured in accordance to FDA guidance and USP 41-NF-36 dissolution method for aripiprazole tablets, wherein $900 \mathrm{ml}$ of $0.1 \mathrm{~N} \mathrm{HCl}$ was recommended as the dissolution medium. In vitro drug release from F1-F10 formulations was determined using USP dissolution apparatus-II. Hard gelatin capsules filled with liquid SMEDDS formulation were introduced into the dissolution media $(0.1 \mathrm{~N} \mathrm{HCl})$ stirred at $50 \mathrm{rpm}$. Samples were withdrawn at 5, 15, 30, 45 and 60 min intervals. The absorbance was measured in a UV spectrometer at a $\lambda_{\max }$ of $255 \mathrm{~nm}^{[15]}$. The liquid SMEDDS formulation was selected based on the $\%$ transmittance, rate of emulsification, clarity, drug loading capacity and dissolution profile.

\section{Preparation of solid SMEDDS formulation:}

Solid adsorption method is one of the best methods to convert a liquid SMEDDS to solid SMEDDS. In this method, an adsorbent acts as a solid carrier and assists in absorbing the liquid SMEDDS to become a fine powder. In the present study, $500 \mathrm{mg}$ of crospovidone 
was added to the selected liquid SMEDDS formulation (F2) mixed in a mortar and pestle and the damp mass was passed through sieve no. 120. It was dried at room temperature. The resulting powder was then directly filled into capsules ${ }^{[16]}$.

\section{Evaluation studies of solid SMEDDS}

Solid SMEDDS (100 mg) was added to $15 \mathrm{ml}$ of distilled water in a volumetric flask, the flask was inverted and the contents were shaken gently to form a fine emulsion, which was kept for $12 \mathrm{~h}$ at room temperature to observe any phase separation. The process was then repeated for liquid SMEDDS ${ }^{[17]}$.

The particle size of emulsion was determined using a Zeta sizer 7.1 (Malvern Instruments, UK) dynamic light scattering particle size analyzer at a wavelength of $635 \mathrm{~nm}$ and at a scattering angle of $173^{\circ}$ at $24.9^{\circ}$. The process was repeated for the liquid SMEDDS ${ }^{[18]}$. The surface morphology of the solid SMEDDS was examined under a S-4100 scanning electron microscope. The sample was fixed on a brass stub using double sided adhesive tape and was made electrically conductive by coating in vacuum $(6 \mathrm{~Pa})$ with platinum (6 $\mathrm{nm} / \mathrm{min}$ ) using a Hitachi Ion Sputter (E-1030) for $240 \mathrm{~s}$ at $15 \mathrm{~mA}^{[19]}$. The physical state of aripiprazole in solid SMEDDS was characterized in a differential scanning calorimeter (Mettler-Toledo star 822e system, Switzerland). Approximately $3 \mathrm{mg}$ of the sample was placed in an aluminium pan, hermetically sealed and heated over a temperature range of $30^{\circ}-190^{\circ}$ at a ramp speed of $30^{\circ} / \mathrm{min}$ under a constant nitrogen flow of $50 \mathrm{~cm}^{3} / \mathrm{min}$. The instrument was calibrated using standard indium, wherein the indium pellet was placed in the aluminium pan and heated at $120-180^{\circ}$ at a speed of $10 \mathrm{~K} / \mathrm{min}$, under nitrogen flow of $50 \mathrm{~cm}^{3} / \mathrm{min}^{[20]}$.

Drug release from solid SMEDDS was performed in in $900 \mathrm{ml}$ of $0.1 \mathrm{~N} \mathrm{HCl}$ as dissolution medium. The USP dissolution apparatus type II with at $37 \pm 0.5^{\circ}$ at a paddle speed of $50 \mathrm{rpm}$. Drug-loaded solid SMEDDS (equivalent to $5 \mathrm{mg}$ of aripiprazole), $5 \mathrm{mg}$ of pure aripiprazole and a marketed product of aripiprazole were placed in the dissolution flask. An aliquot $(5 \mathrm{ml})$ of the sample was collected at 5, 10, 15, 30, 45 and 60 min time intervals; filtered and analyzed for the content using UV spectroscopy. An equivalent volume of fresh dissolution medium was added to maintain sink condition $^{[20]}$.

A stability study of the selected solid SMEDDS was performed by storing it in screw-capped glass bottles at a temperature and relative humidity of $37^{\circ}$ and $60 \%$ (RH), $40^{\circ} / 75 \% \mathrm{RH}$ for a period of $1 \mathrm{mo}$. Samples were withdrawn periodically at 5, 10, 20 and $30 \mathrm{~d}$.

\section{RESULTS AND DISCUSSION}

This investigation attempts to prepare SMEDDS of aripiprazole using IPM, propylene glycol and Tween 80. Particle size and zeta potential of the prepared SMEDDS were analysed along with drug loading capacity and in vitro release of the payload.

FT-IR spectra of aripiprazole was recorded to check the compatibility of aripiprazole with excipients. Characteristic absorption bands in IR regions are shown in the fig. 1. Aripiprazole showed characteristic peaks at $3437 \mathrm{~cm}^{-1}$ due to $\mathrm{N}-\mathrm{H}$ stretching vibration, $\mathrm{C}-\mathrm{H}$ stretch occurs at $2945,1676 \mathrm{~cm}^{-1}$ due to carbonyl stretching vibration, C-N stretch shows at $1197 \mathrm{~cm}^{-1}$ and a peak at $775 \mathrm{~cm}^{-1}$ due to the $\mathrm{C}-\mathrm{Cl}$ stretch. All the above characteristic peaks appeared in the spectra of physical mixture. The FTIR studies indicated that there was no chemical interaction or modification between aripiprazole and crospovidone, Tween 80, IPM and propylene glycol. The excipients were selected based on the saturation solubility studies and the safety profiles. Oil is the most important excipient as it can facilitate self-emulsification and can increase the fraction of a lipophilic drug transported via the intestinal lymphatic system, thereby increasing absorption from the GI tract. Amongst the individual oils, the saturation solubility of aripiprazole in IPM $(9.12 \mathrm{mg} / 2 \mathrm{ml})$ was observed to be far superior compared to that in other oils followed

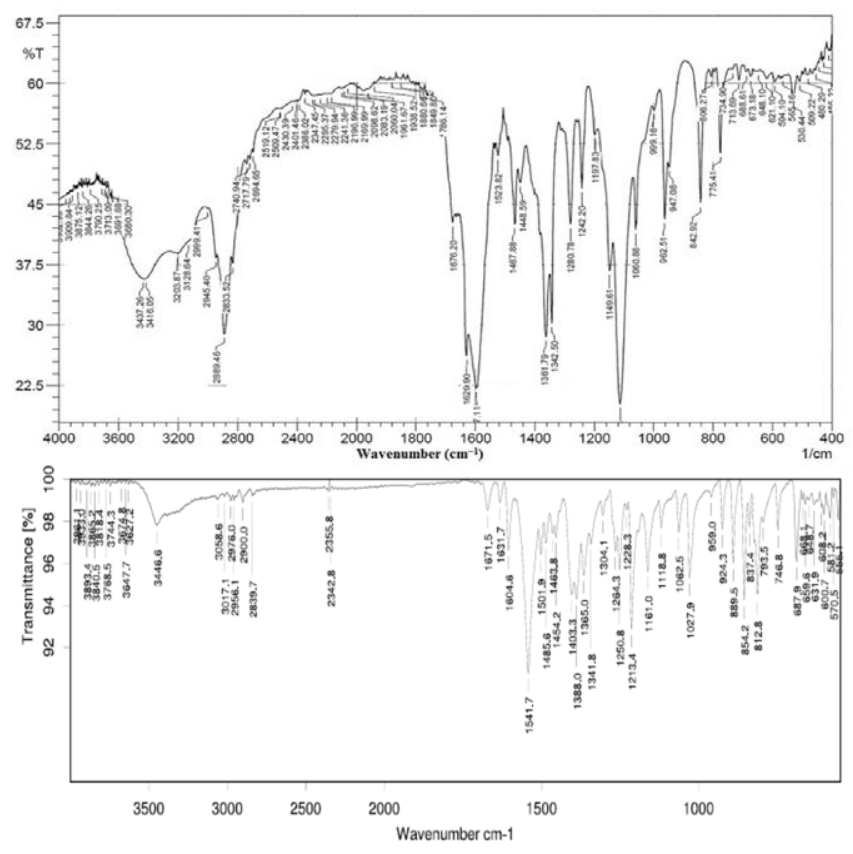

Fig. 1: FTIR spectra of the drug, physical mixture 


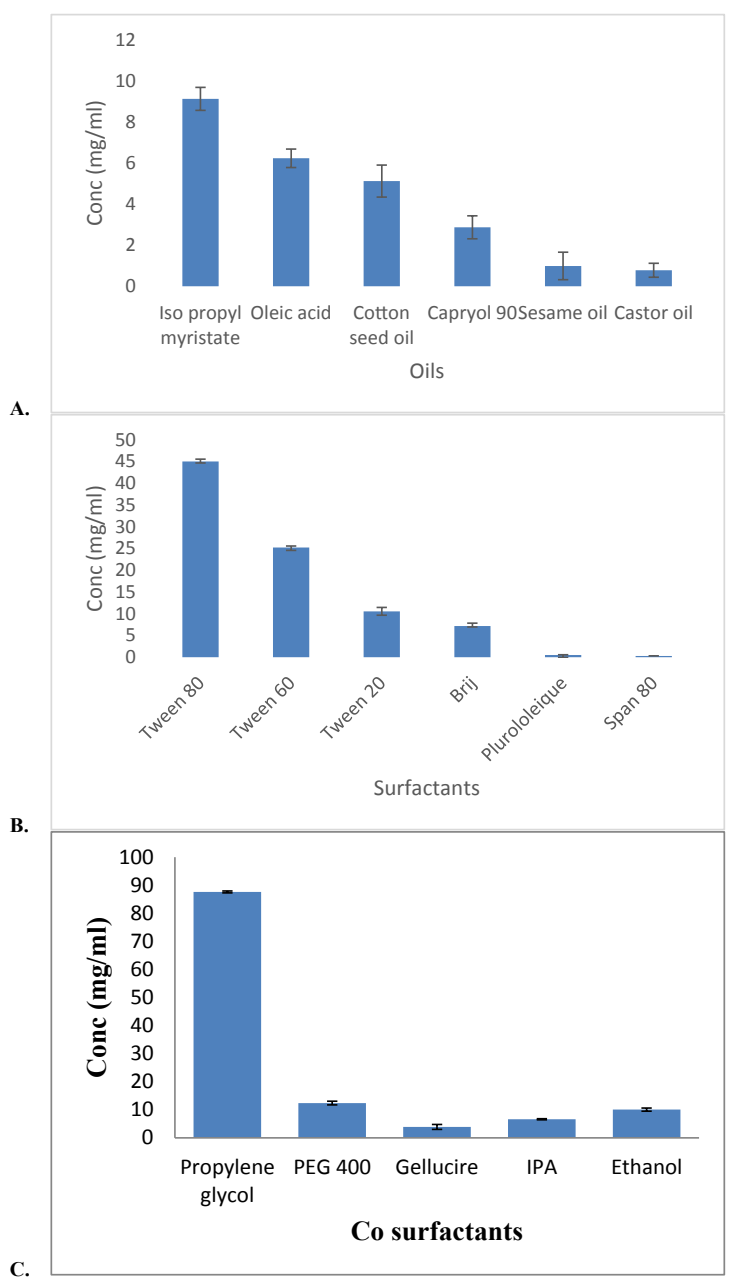

Fig. 2: Solubility studies of aripiprazole

Solubility of aripiprazole in (A) oils, (B) surfactants and (C) co-surfactants

by oleic acid and cotton seed oil as shown in fig. 2A. Surfactants assist the immediate formation of $\mathrm{o} / \mathrm{w}$ droplets and/or rapid spreading of the formulation in the aqueous media.

Mostly, non-ionic surfactants are used as these are known to be less toxic and less affected by $\mathrm{pH}$ and ionic strength as compared to ionic surface-active agents. Amongst the surfactants, the saturation solubility of aripiprazole in Tween $80(45 \mathrm{mg} / \mathrm{ml})$ was greater than other surfactants is given in fig. $2 \mathrm{~B}$. The cosurfactant along with the surfactant lowers the interfacial tension to a very small and transient negative value. Amongst the cosurfactants, the saturation solubility of aripiprazole in propylene glycol was $87.6 \mathrm{mg} / \mathrm{ml}$ as given in fig. $2 \mathrm{C}$. It was observed that the selected excipients were miscible with each other and formed a homogenous mixture. From the selected surfactants and cosurfactants, surfactant-cosurfactant mix, $\mathrm{S}_{\text {mix }}$ (surfactant:Tween80) and cosurfactant (propylene glycol) was prepared. The clarity test was performed at different ratios of $\mathrm{S}_{\text {mix }}$. Out of the combinations studied,
$2: 1,3: 1,4: 1,1: 2$ mixtures showed the highest level of clarity and self-emulsification power (Table 1). These ratios were then further selected for constructing the ternary diagram.

The ternary phase diagram was prepared using $\mathrm{S}_{\text {mix }}$ ratios, 2:1, 3:1 and 4:1. The oil: $\mathrm{S}_{\text {mix }}$ ratios of 9:1, 8:2, $7: 3,6: 4,5: 5,4: 6,3: 7,2: 8$ and 1:9 were selected and titrated against distilled water. The SMEDDS possess an important characteristic of drug precipitation on dilution with water due to loss of solvent capacity. Selection of oil and surfactant and the mixing ratio of oil and other components plays an important role in the formulation of SMEDDS. Therefore the phase behavior

TABLE 1: SCREENING OF $S_{\text {mix }}$ RATIOS FOR PHYSICAL APPEARANCE

\begin{tabular}{|c|c|c|c|c|}
\hline \multirow{2}{*}{ Oil:S mix $_{\text {(ratio) }}$} & \multicolumn{4}{|c|}{$S_{\text {mix }}$} \\
\hline & $1: 1$ & $2: 1$ & $3: 1$ & 4: \\
\hline$\overline{9: 1}$ & $\mathrm{H}$ & C & C & C \\
\hline $8: 2$ & $\mathrm{H}$ & C & C & C \\
\hline $7: 3$ & $\mathrm{H}$ & C & C & C \\
\hline $6: 4$ & $\mathrm{H}$ & C & C & $C$ \\
\hline $5: 5$ & $\mathrm{H}$ & C & C & C \\
\hline $4: 6$ & C & C & C & C \\
\hline $3: 7$ & C & C & C & C \\
\hline $2: 8$ & $C$ & $C$ & $C$ & $C$ \\
\hline $1: 9$ & $C$ & $C$ & $C$ & $C$ \\
\hline
\end{tabular}

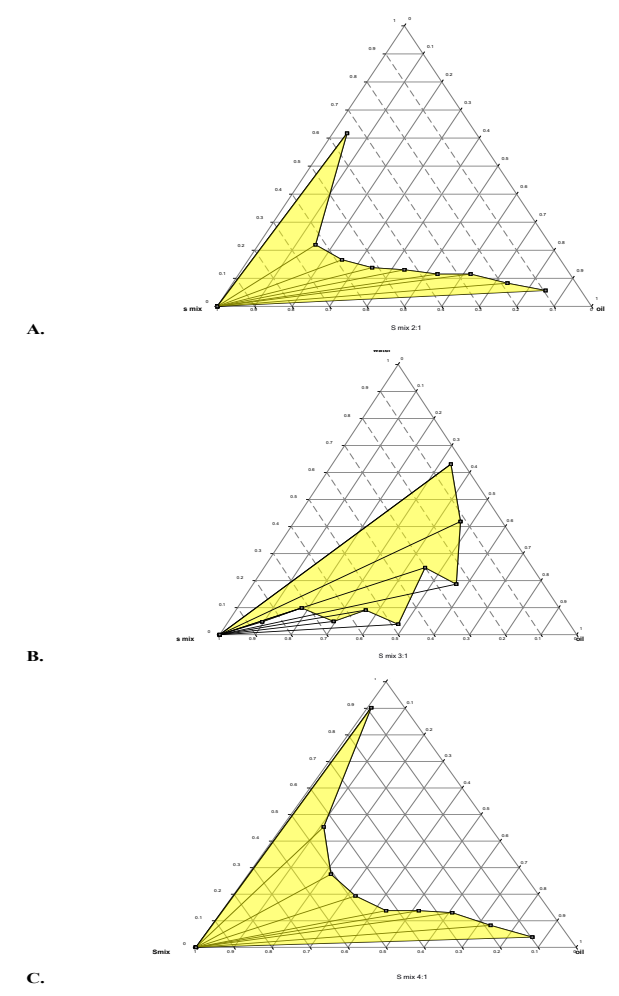

Fig. 3: Phase diagrams

Phase diagrams of $S_{\text {Mix }}$ (A: 2:1, B: 3:1, C: 4:1) isopropyl myristate/Tween 80/propylene glycol 
of each SMEDDS was carefully studied using the phase diagram constructed by using PROSIM software as a guide as given in fig. 3A, B and C. The microemulsion phase was visually identified as the area where clear and transparent formulations are obtained on dilution with water. The phase diagram also helped to establish micro emulsifying capacity. It was found that the $\mathrm{S}_{\text {mix }}$ ratio in $2: 1,3: 1$, and $4: 1$ showed the maximum microemulsion zone. Hence, these ratios were selected for the formulation. The selected $\mathrm{S}_{\text {mix }}$ and oil was titrated against distilled water (Table 2). It was observed that increasing the concentration of the surfactant with respect to the cosurfactant in SMEDDS formulation decreased the spontaneity of the self-emulsification process. Higher concentration of surfactant lowered the self-emulsifying region in the phase diagram.

Altogether 10 SMEDDS formulations were prepared by selection of suitable concentration ranges of oil (10$30 \%$ ) and $\mathrm{S}_{\text {mix }}(90-70 \%)$ from the phase diagram based on weight. To this, $5 \mathrm{mg}$ of aripiprazole was added. These formulations were analysed for aripiprazole loading capacity and evaluated for clarity, dispersibility, percent drug content and in vitro drug release (Table 3 ). All 10 formulations appeared to be clear and transparent and were yellowish to pale yellow color. The clarity was expressed as \% transmittance, where absorbance and $\%$ transmittance was noted at 650 and $400 \mathrm{~nm}$. The best results have been reported for all the formulations at $650 \mathrm{~nm}$ compared to $400 \mathrm{~nm}$. The $\%$ transmission was more than $90 \%$ for all the formulations except F3, F5, and F9. The best transmittance was reported for F2, which was found to be $99.55 \%$ (Table 4). For optically clear solutions; higher transmittance was observed whereas cloudier dispersion led to lower transmittance. The low absorbance of optically clear dispersion is due to the oil droplets in a state of finer dispersion.

Drug content of the selected SMEDDS formulation batch F2 for ratio 2:1 was found to be the highest i.e. $98.5 \pm 0.304 \%$. For $3: 1$ ratio the drug content ranged from $84.2 \pm 0.11-101.4 \pm 0.05 \%$, 4:1 ratio showed drug content from $90.0 \pm 0.23$ to $97.1 \pm 0.01 \%$. Therefore, F2 was considered as a suitable batch for further

TABLE 2: COMPOSITION OF OIL, $S_{\text {mix }}$ AND WATER FOR PHASE DIAGRAM

\begin{tabular}{|c|c|c|c|c|c|c|}
\hline Oil (g) & $\mathrm{S}_{\text {mix }}(\mathrm{g})$ & Water (g) & Total & $\mathrm{S}_{\text {mix }}(\%)$ & Oil (\%) & Water (\%) \\
\hline 0.1 & 0.9 & 0.04 & 1.04 & 86.5 & 9.61 & 3.84 \\
\hline 0.2 & 0.8 & 0.09 & 1.09 & 73.3 & 18.08 & 8.25 \\
\hline 0.3 & 0.7 & 0.15 & 1.15 & 60.86 & 26.08 & 13.04 \\
\hline 0.4 & 0.6 & 0.16 & 1.16 & 51.72 & 34.48 & 13.79 \\
\hline 0.5 & 0.5 & 0.16 & 1.16 & 43.1 & 43.1 & 13.79 \\
\hline 0.6 & 0.4 & 0.24 & 1.24 & 32.25 & 48.38 & 19.35 \\
\hline 0.7 & 0.3 & 0.38 & 1.38 & 21.73 & 50.72 & 27.53 \\
\hline 0.8 & 0.2 & 0.83 & 1.83 & 10.92 & 13.71 & 45.35 \\
\hline 0.9 & 0.1 & 9.24 & 10.24 & 0.97 & 8.78 & 90.24 \\
\hline Oil (g) & $\mathrm{S}_{\text {mix }}(\mathrm{g})$ & Water $(\mathrm{g})$ & Total (g) & $\mathrm{S}_{\text {mix }}(\%)$ & Oil (\%) & Water (\%) \\
\hline 0.1 & 0.9 & 0.05 & 1.05 & 85.71 & 9.72 & 4.67 \\
\hline 0.2 & 0.8 & 0.11 & 1.11 & 72.07 & 18.01 & 9.9 \\
\hline 0.3 & 0.7 & 0.05 & 1.05 & 63.63 & 28.53 & 4.76 \\
\hline 0.4 & 0.6 & 0.1 & 1.1 & 54.54 & 36.36 & 9.09 \\
\hline 0.5 & 0.5 & 0.04 & 1.04 & 48.07 & 48.07 & 3.84 \\
\hline 0.6 & 0.4 & 0.33 & 1.33 & 30.07 & 45.11 & 24.81 \\
\hline 0.7 & 0.3 & 0.23 & 1.23 & 24.39 & 56.91 & 18.69 \\
\hline 0.8 & 0.2 & 0.72 & 1.72 & 11.62 & 46.5 & 41.86 \\
\hline 0.9 & 0.1 & 1.71 & 2.71 & 3.69 & 33.21 & 63.09 \\
\hline Oil (g) & $\mathrm{S}_{\text {mix }}(\mathrm{g})$ & Water (g) & Total (g) & $\mathrm{S}_{\text {mix }}(\%)$ & Oil (\%) & Water (\%) \\
\hline 0.1 & 0.9 & 0.06 & 1.06 & 84.90 & 9.43 & 5.66 \\
\hline 0.2 & 0.8 & 0.16 & 1.16 & 68.96 & 17.24 & 13.79 \\
\hline 0.3 & 0.7 & 0.14 & 1.14 & 61.40 & 26.31 & 12.28 \\
\hline 0.4 & 0.6 & 0.16 & 1.16 & 51.72 & 34.48 & 13.79 \\
\hline 0.5 & 0.5 & 0.68 & 1.68 & 29.76 & 29.76 & 40.47 \\
\hline 0.6 & 0.4 & 0.34 & 1.34 & 29.85 & 44.77 & 25.37 \\
\hline 0.7 & 0.3 & 0.43 & 1.43 & 20.97 & 48.95 & 30.06 \\
\hline 0.8 & 0.2 & 1.37 & 2.37 & 8.43 & 33.75 & 57.80 \\
\hline Eoricentr & $\theta=1,3$ & :1) Andowate & ruction 61 of & amf.77 & 24.93 & 72.29 \\
\hline
\end{tabular}


evaluation (Table 5). The formulations were added to $250 \mathrm{ml}$ of distilled water in a beaker and stirred at $50 \mathrm{rpm}$ on a magnetic stirrer to aid emulsification. The emulsification was spontaneous with transparent bluish white appearance as given in Table 5. This suggested that the formulation would remain as a microemulsion when dispersed in GIT. This fine dispersion of formulation increased the surface area for drug dissolution and presents the drug in a dissolved state, thereby improving the absorption of the drug.

All the formulations were tested for phase separation studies. Only F3 and F9 showed phase separation after $24 \mathrm{~h}$, which can be attributed to the high concentration

TABLE 3: SELECTED FINAL FORMULATIONS

\begin{tabular}{lccc}
\hline Formulation code & $\mathrm{S}_{\text {mix }}(\mathbf{g})$ & Oil $(\mathrm{g})$ & Water $(\mathrm{g})$ \\
\hline F1 & 0.902 & 0.072 & 0.031 \\
F2 & 0.801 & 0.022 & 0.176 \\
F3 & 0.703 & 0.095 & 0.203 \\
F4 & 1 & 0 & 0 \\
F5 & 0.763 & 0.081 & 0.156 \\
F6 & 0.854 & 0.047 & 0.097 \\
F7 & 0.926 & 0.024 & 0.048 \\
F8 & 0.732 & 0.088 & 0.178 \\
F9 & 0.861 & 0.037 & 0.101 \\
F10 & 0.931 & 0.032 & 0.035 \\
\hline
\end{tabular}

TABLE 4: PERCENT TRANSMITTANCE OF SMEDDS FORMULATION

\begin{tabular}{|c|c|c|c|c|}
\hline \multirow{2}{*}{$\begin{array}{l}\text { Formulation } \\
\text { code }\end{array}$} & \multicolumn{2}{|c|}{ Dilution 1:10 } & \multicolumn{2}{|c|}{ Dilution 1:250 } \\
\hline & At $650 \mathrm{~nm}$ & At $400 \mathrm{~nm}$ & At $650 \mathrm{~nm}$ & At $400 \mathrm{~nm}$ \\
\hline$\overline{\mathrm{F} 1}$ & 94.49 & 82.65 & 98.86 & 92.01 \\
\hline F2 & 98.40 & 87.59 & 99.55 & 94.06 \\
\hline F3 & 97.45 & 84.91 & 96.34 & 88.81 \\
\hline F4 & 99.90 & 86.60 & 99.32 & 93.49 \\
\hline F5 & 96.78 & 70.35 & 100.37 & 86.54 \\
\hline F6 & 95.55 & 85.65 & 99.89 & 92.83 \\
\hline F7 & 97.89 & 85.25 & 100.58 & 92.80 \\
\hline F8 & 95.61 & 85.22 & 99.00 & 91.22 \\
\hline F9 & 96.21 & 75.14 & 97.56 & 87.45 \\
\hline F10 & 93.39 & 81.12 & 97.14 & 91.24 \\
\hline
\end{tabular}

TABLE 5: EVALUATION OF LIQUID SMEDDS

\begin{tabular}{|c|c|c|c|c|c|c|c|}
\hline $\begin{array}{l}\text { Formulation } \\
\text { code }\end{array}$ & $\mathrm{pH}$ & $\begin{array}{c}\text { Phase } \\
\text { separation }\end{array}$ & $\begin{array}{c}\text { Self-emulsification } \\
\text { time (min) }\end{array}$ & $\begin{array}{c}\text { Cloud point } \\
\left({ }^{\circ}\right)\end{array}$ & $\begin{array}{l}\text { Drug content } \\
\text { (mg) }\end{array}$ & $\begin{array}{c}\text { Drug content } \\
\text { (\%) }\end{array}$ & $\begin{array}{c}\text { Drug loading } \\
(\mathrm{mg} / \mathrm{ml})\end{array}$ \\
\hline $\mathrm{F}_{1}$ & 5.8 & - & $<1$ & 75 & 4.64 & $92.8 \pm 0.01$ & $134.59 \pm 0.12$ \\
\hline$F_{2}$ & 5.8 & - & $<1$ & 70 & 4.92 & $98.5 \pm 0.01$ & $152.00 \pm 0.33$ \\
\hline $\mathrm{F}_{3}$ & 5.3 & + & $>1$ & 85 & 5.07 & $101.4 \pm 0.05$ & $138.63 \pm 0.11$ \\
\hline $\mathrm{F}_{4}$ & 4.3 & - & $<1$ & 90 & 4.21 & $84.2 \pm 0.11$ & $130.30 \pm 0.08$ \\
\hline$F_{5}$ & 4.8 & - & $<1$ & 70 & 4.71 & $94.2 \pm 0.11$ & $116.16 \pm 0.23$ \\
\hline $\mathrm{F}_{6}$ & 5.5 & - & $<1$ & 75 & 4.45 & $90 \pm 0.12$ & $121.46 \pm 0.09$ \\
\hline $\mathrm{F}_{7}$ & 5.6 & - & $<1$ & 70 & 4.78 & $95.7 \pm 0.061$ & $121.71 \pm 0.11$ \\
\hline $\mathrm{F}_{8}$ & 5.3 & - & $<1$ & 75 & 4.85 & $97.1 \pm 0.01$ & $127.02 \pm 0.2$ \\
\hline$F_{9}$ & 5.0 & + & $>1$ & 90 & 4.50 & $90.0 \pm 0.23$ & $138.38 \pm 0.31$ \\
\hline$F_{10}^{y}$ & 5.2 & - & $<1$ & 85 & 4.63 & $92.8 \pm 0.31$ & $146.02 \pm 0.01$ \\
\hline
\end{tabular}

of surfactant. The $\mathrm{pH}$ of the final formulations was in the range of 4 to 6 (Table 5). The cloud point is the temperature above which an aqueous solution of water soluble surfactant, especially non-ionic, becomes turbid. It is an indicator of the successful formation of a stable microemulsion above which an irreversible phase separation occurs. The reason for the cloudiness above this temperature is due to the fact that polyethylene oxide of the Tween undergoes dehydration. It is suggested that the cloud point for SMEDDS should be above $37^{\circ}$ to avoid phase separation occurring in the gastrointestinal tract. The cloud point for all the 10 formulations was above $70^{\circ}$, which showed that the formulations would remain stable at body temperature (Table 5).

The drug loading studies were conducted for all the formulations to determine the maximum drug solubility and intake. The results presented a clear evidence that drug loading decreased when the concentration of oil was increased. F2 showed the highest drug loading capacity (152.00 mg/ml, Table 5).

The surface charge or the zeta potential of the dispersed systems plays an important role with respect to bioavailability and stability. As far as bioavailability is concerned, if the surface charge of the droplets is positive, the positive charges interact with the negatively charged mucin layer. This leads to an increased absorption of the administered drug and hence improves bioavailability. Such observations were found true in case of the coarse emulsions. The magnitude of the zeta potential gives an indication of the potential stability of the colloidal system. If all the particles have a large negative or positive zeta potential, they will repel each other and there is dispersion stability. For the selected formula (F2), zeta potential was found to be $-25.8 \mathrm{mV}$ (fig. 4), which was closer to $-30 \mathrm{mV}$ as given in fig. 4. The zeta potential values above $\pm 30 \mathrm{mV}$ are an indication of ultimate stability as the system prevents aggregation of the droplets. 
The droplet size of the microemulsion is important, since it determines the rate and extent of drug release and absorption. The drug can diffuse faster from smaller droplets into the aqueous phase, thereby increasing the drug dissolution. Smaller droplets size present larger surface area for the drug absorption. The formulations exhibited an average droplet size of $61.22 \mathrm{~nm}$ (fig. 5). This ensures that upon dilution in gastrointestinal fluids, the formulation gets converted to a microemulsion with nano-sized globules. The polydispersity index (PDI) of samples was found to be below 0.453 as given in fig. 5. Moreover, it was observed that an increase in surfactant concentration decreases the droplet size up to a certain extent, but thereafter, any further increase in surfactant concentration results in an increase in droplet size. The reduction in droplet size can be attributed to the stabilization of oil droplets due to localization of surfactant monolayers at the oil-water interface.

For the drug release studies, $0.1 \mathrm{~N} \mathrm{HCl}$ was used as the dissolution media. The $\%$ drug release after $1 \mathrm{~h}$ for formulations F1-F10 varied from $91.04 \pm 0.11$ to $98.32 \pm 0.164 \%$ (fig. 5) as compared to $32.54 \pm 0.142 \%$ for the pure drug. The initial release of the drug from the formulations was faster when compared to that of the pure drug. Formulation F2 showed an initial $\%$ drug release of $90.22 \pm 0.541 \%$, whereas the pure drug showed a release of $12.21 \pm 0.321 \%$ as shown in fig. 6. Micellar solubilization and/or enhanced contact surface might be responsible for the increase in drug

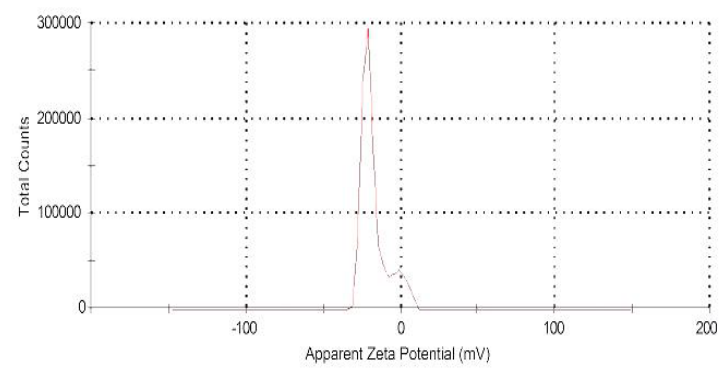

A.

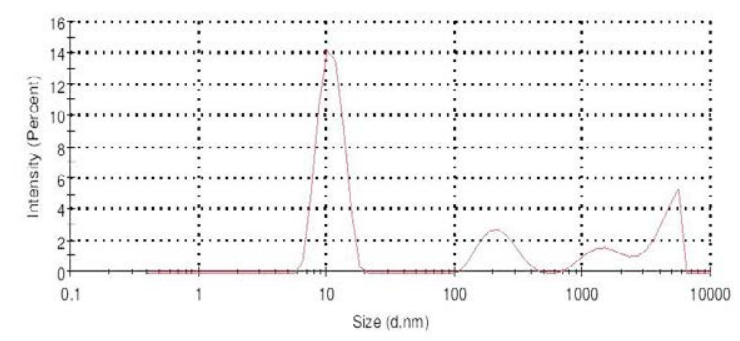

B.

Fig. 4: Zeta potential and particle size distribution of selected liquid SMEDDS formula

(A) Zeta potential and (B) particle size distribution

November-December 2019

Indian Journal of Pharmaceutical Sciences

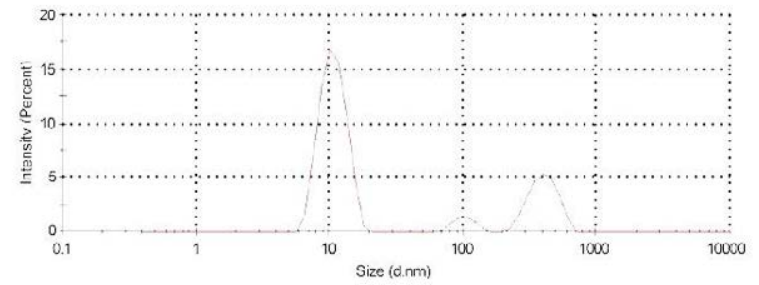

A.

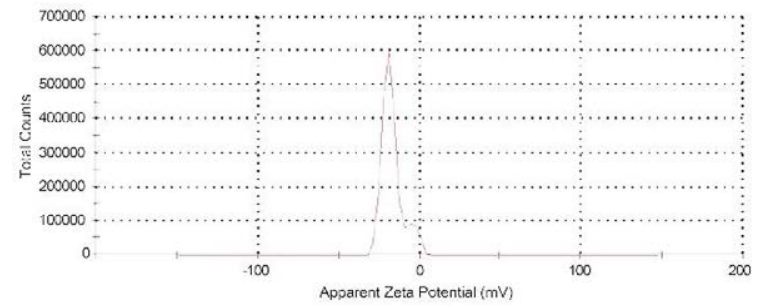

B.

Fig. 5: Particle size and zeta potential of solid SMEDDS (A) particle size analysis and (B) zeta potential

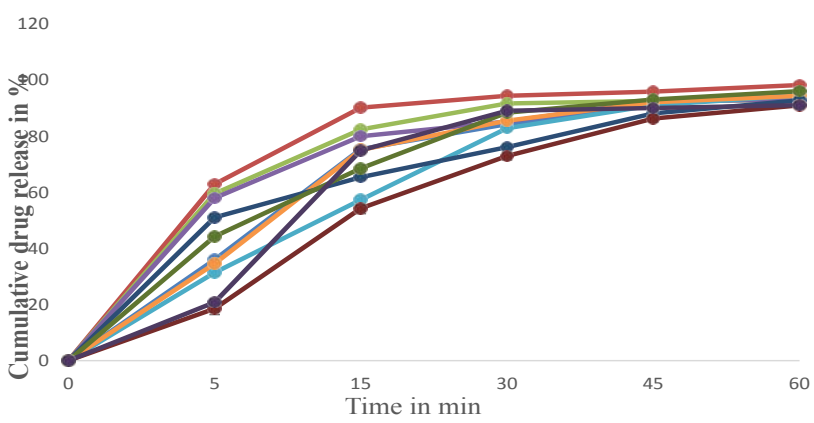

Fig. 6: Drug release profile of SMEDDS

SMEDDS formulations F1 (-० - ), F2 (-०-), F3 (-०-), F4 $(-0-)$ and F5 (-० -)

release from SMEDDS. The rapid release of the drug from the oil droplets suggested that the polarity of the oil and the $\log \mathrm{P}$ value of the model drug was appropriate, thus enabling the drug to partition out from the oil droplet. This establishes that micro emulsions can effectively increase the drug dissolution rate of drugs that have poor water-solubility and can be formulated as an immediate release dosage form for these drugs.

SMEDDS have some disadvantages such as incompatibility with the gelatin shells and subsequent leakage from the shells. To overcome these disadvantages, SMEDDS were converted in to a solid via adsorption on to a solid carrier. The solid SMEDDS can be filled easily into hard gelatin capsules or can be administered in other forms such as pellets, tablets and these show a fair amount of stability because of their solid nature.

The optimized formulation F2 was found to be the best formulation based on certain evaluation parameters such as clarity, rate of emulsification, drug content, 
dispersibility and in vitro dissolution profile. F2 was converted to solid SMEDDS using the adsorption technique. Different types of adsorbents were employed such as microcrystalline cellulose, lactose, magnesium hydroxide, talc and crospovidone in different ratios. Compared to other adsorbents, crospovidone displayed good adsorption efficiency with a good mixing ability and free flowing properties in the ratio of 1:0.5. Therefore, solid SMEDDS were prepared using crospovidone carrier and evaluated further (Table 6). The drug content of the solid SMEDDS formulation was found to be $93.22 \pm 0.304 \%$. The micromeritics properties of solid SMEDDS are shown in Table 6.

The droplet size of solid SMEDDS formulation after reconstitution with distilled water (10 times dilution) was seen to be $119.5 \mathrm{~nm}$, which was slightly higher than liquid SMEDDs $(61.22 \mathrm{~nm})$. The PDI of solid SMEDDS was found to be 0.449 , which was under the acceptance criteria as given in fig.5. This indicated that the droplet was uniform in size with a smaller aggregation of droplets, thereby ascertaining the stability. Thus, a fairly monodisperse emulsion was formed upon dilution with gastric fluid and the formulation would remain stable. Zeta potential was found to be -24.3 , which was similar to that of the liquid SMEDDS (fig. 5). Drug can diffuse faster from small droplets into aqueous phase, thereby increasing the drug dissolution. Smaller droplet size presents a larger surface area for drug absorption. As a result, SMEDDS presents drug in a small droplet form, which assists in a well-proportioned distribution and increase in dissolution.

The surface topology was studied using scanning electronic microscopy. The SEM images of solid SMEDDS showed well separated particles with no agglomeration. Irregular shape and size of the solid

TABLE 6: COMPOSITION AND EVALUATION OF SOLID SMEDDS

\begin{tabular}{lc}
\hline Ingredients & Quantity taken \\
\hline Aripiprazole & $5 \mathrm{mg}$ \\
Isopropyl myristate & $0.2 \mathrm{ml}$ \\
Tween 80 & $0.54 \mathrm{ml}$ \\
Propylene glycol & $0.26 \mathrm{ml}$ \\
Crospovidone & $500 \mathrm{mg}$ \\
Evaluation of S-F2 & \\
Bulk density $(\mathrm{g} / \mathrm{ml})$ & 0.33 \\
Tapped density $(\mathrm{g} / \mathrm{ml})$ & 0.49 \\
Carr's index $(\%)$ & 17.5 \\
Angle of repose $\left({ }^{\circ}\right)$ & 36 \\
Hausner ratio & 1.22 \\
Drug content $\pm S D(\%)$ & $93.22 \pm 0.304$ \\
\hline S &
\end{tabular}

$\mathrm{S}-\mathrm{F} 2=$ solid SMEDDS of $\mathrm{F} 2$ formulation 1096
SMEDDS was observed in fig. 7. Differential scanning calorimetry was used to investigate the thermal behaviour of the pure aripiprazole and along with excipients. Aripiprazole showed an endothermic peak at $139.97^{\circ}$ with onset at $138.51^{\circ}$ and end at $141.91^{\circ}$ that corresponded to the melting point of aripiprazole. It was

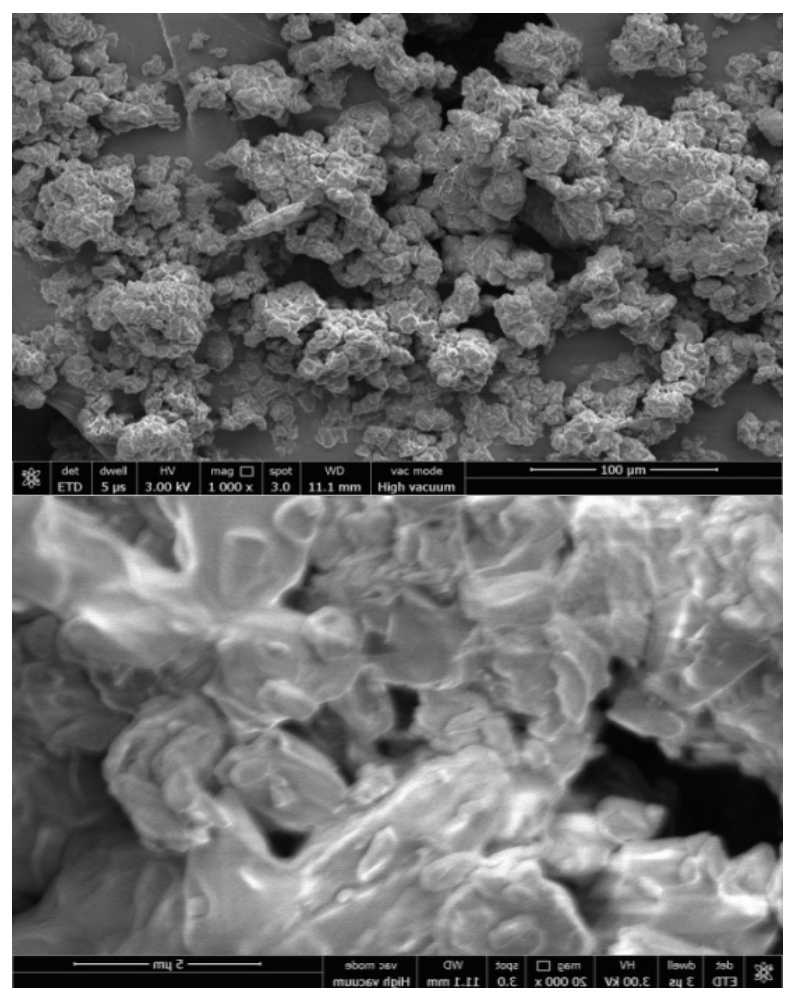

Fig. 7: SEM photomicrographs of solid SMEDDS

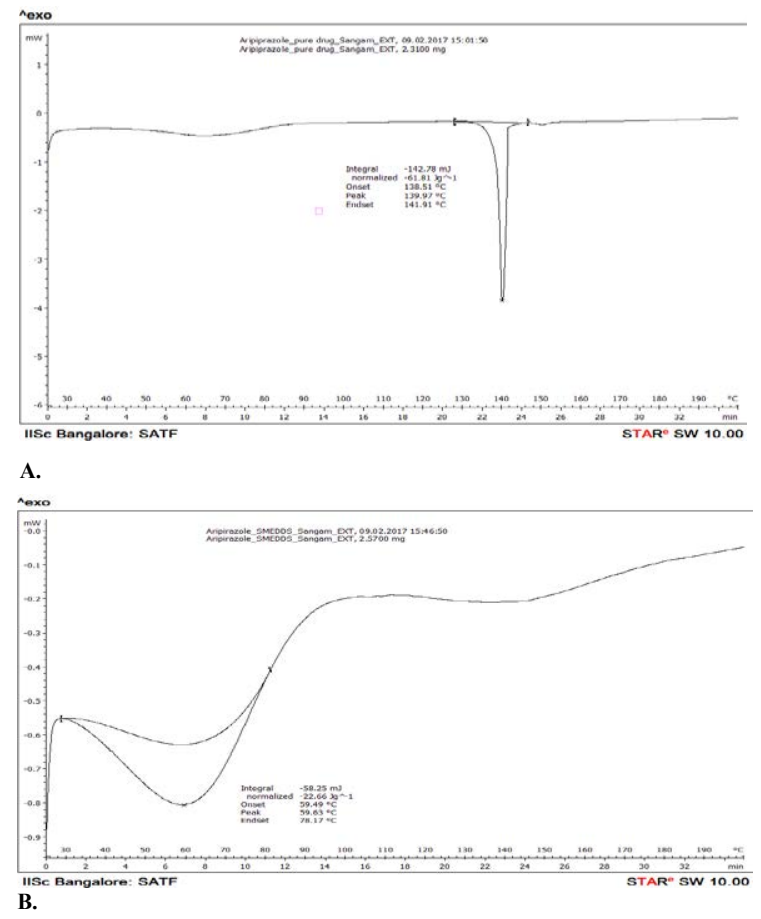

Fig. 8: DSC thermograms aripiprazole and SMEDDS DSC thermograms of (A) aripiprazole and (B) selected SMEDDS formula

Indian Journal of Pharmaceutical Sciences 
TABLE 7: PERCENT DRUG CONTENT AFTER STABILITY STUDIES

\begin{tabular}{lccc}
\hline Formulation code & Drug content \pm SD & $30 \pm 2^{\circ} / 60 \pm 5 \% \mathrm{RH}$ & $40 \pm 2^{\circ} / 70 \pm 5 \% \mathrm{RH}$ \\
\hline F2 & $98.5 \pm 0.23$ & $98.25 \pm 0.11$ & $97.81 \pm 0.10$ \\
S-F2 & $93.22 \pm 0.3$ & $93.22 \pm 0.3$ & $92.22 \pm 0.05$ \\
\hline
\end{tabular}

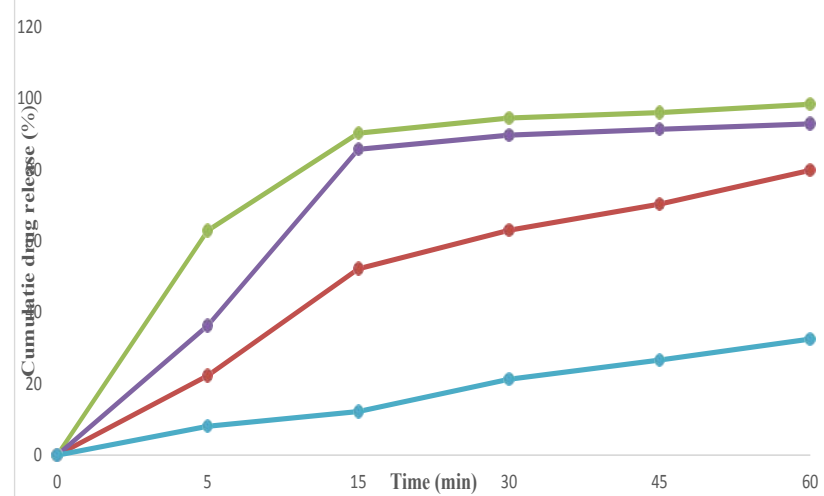

Fig. 9: Comparative in vitro release profiles

Comparative in vitro release profile of pure drug (-०-), marketed formulation (-๑), optimized liquid SMEDDS $(-\bullet-)$ and solid SMEDDS (-०-)

noticed that there was a shift in the melting point from $139^{\circ}$ to $59.63^{\circ}$ (figs. 8 and 9). This further contributes to the high aqueous solubility of the formulation and increased dissolution rate as shown in fig. 8. The $\%$ cumulative drug release from the selected solid SMEDDS formulation was found to be $92.84 \pm 0.1488$, which was 3 times higher when compared to that of the pure drug and is superior to that of the commercially available Arip 5 mg (fig. 9).

Short term stability studies indicated that there was no evident change in the physical appearance of formulation at the end of a 3 mo storage period at both temperature conditions of $25 \pm 2 \% 60 \pm 5 \% \mathrm{RH}$ and $40 \pm 2^{\circ} / 75 \pm 5 \% \mathrm{RH}$. The drug content of F2 did not significantly change during the study period (Table 7).

In conclusion, the study was undertaken utilizing SMEDDS formulations to overcome the inherent solubility problem of aripiprazole. Isopropyl myristate, Tween 60 and propylene glycol were used as oil, surfactant and co-surfactant, respectively to prepare the SMEDDS formula. The formulations, which showed superior drug content, drug loading, zeta potential and globule size distribution were converted to solid SMEDDS using crospovidone, as solid SMEDDS display a higher level of stability in comparison to liquid SMEDDS. The drug release profile from both solid and liquid SMEDDS was greater in comparison to Arip $5 \mathrm{mg}$ and was superior to pure aripiprazole. The results of the study indicated that SMEDDS could enhance solubility, dissolution rate and therapeutic efficacy of poorly soluble drugs and could be prepared using biocompatible excipients and a cost-effective hassle-free process.

\section{Acknowledgements:}

The authors thank the management of Krupanidhi College of Pharmacy for their support in conducting the research work and Watson India Ltd for providing the gift sample of aripiprazole.

\section{Conflict of interest:}

There are no conflicts of interest.

\section{REFERENCES}

1. Tiwari G, Rai A, Tiwari R. Self-emulsifying drug delivery system: an approach to enhance solubility. Syst Rev Pharm 2010;1(2):133-40.

2. Amidon GL, LennernasH, Shah VP, Crison JR. Theoretical basis for a biopharmaceutics drug classification: the correlation of in vitro drug product dissolution and in vivo bioavailability. Pharm Res 1995;12:413-20.

3. Tripathi KD. Essentials of Pharmacology. $6^{\text {th }}$ ed. New Delhi; Jaypee Brother Medical Publishers Pvt. Ltd.; 2008. p. 57.

4. Rang H, Dale M, Ritter J, Flower R. Rang and Dale's. Pharmacology. $6^{\text {th }}$ ed. London, United Kingdom: Churchill Livingstone; 2007. p. 545-55.

5. Burris KD, Molski TF, Xu C, Ryan E, Tottori K, Kikuchi T, et al. Aripiprazole, a novel antipsychotic, is a high- affinity partial agonist at human dopamine D2 receptors. J Pharmacol Exp Ther 2002;302:381-9.

6. Glick ID, Duggal VH, Aripiprazole as a dopamine partial agonist. J Clin Psychopharmacol 2006;26:101-3.

7. Pouton CW. Self-emulsifying drug delivery systems: assessment of efficacy of emulsification. Int $\mathrm{J}$ Pharm 1985;7:335-48.

8. Bharathi PR, Jasinth D, Priyanka CHC, Lakshmi BS, Madhavi B, Swathi T. A review: Self-emulsifying drug delivery system. Int J Res Pharm Nano Sci 2013;2;2:203-12.

9. Yetukuri K, Sudheer P. Approaches to development of Solid Self Micron Emulsifying Drug Delivery System: Formulation Techniques and Dosage Forms: A Review. Int J Pharm Sci Res 2012;3;10:3550-58.

10. Patel A, Lalwani A. Self-microemulsifying drug delivery system as a potential drug delivery system for protease inhibitors in the treatment of AIDS. Asian J Pharm Sci 2011;6;5:226-40.

11. Goyal U, Arora R, Aggarwal G. Formulation design and evaluation of a self-micro emulsifying drug delivery system of lovastatin. Acta Pharm 2012; 62:357-70.

12. Balakrishnan P, Lee BJ, Oh DH, Kim JO, Hong MJ, Kim JA, et al. Enhanced oral bioavailability of dexibuprofen by a novel solid self-emulsifying drug delivery system (SEEDS). Eur J Pharm Biopharm 2009;72:539-45.

13. Dahan A, Hoffman A. Rationalizing the selection of oral lipid 
based drug delivery systems by an in vitro dynamic lipolysis model for improved oral bioavailability of poorly water soluble drugs. J Control Release 2008;129:1-10.

14. Weerapol Y, Limmatvapirat S, Kumpugdee-Vollrath M, Sriamornsak P. Spontaneous emulsification of nifedipine loaded self nano-emulsifying drug delivery system. AAPSPharmSciTech 2014;16;2:435-43.

15. Agrawal AG, Kumar A, Guide PS. Self-emulsifying drug delivery system for enhanced solubility and dissolution of Glipizide. Colloids Surf B 2015;126:553-60.

16. Kommuru TR, Gurley B, Khan MA, Reddy IK. Selfemulsifying drug delivery systems (SEDDS) of coenzyme $\mathrm{Q}_{10}$ : Formulation development and bioavailability assessment. Int J Pharm 2001;212;2:233-46.
17. Ping Z, Ying L, Nianping F. Preparation and evaluation of self -micro emulsifying drug delivery system of Oridonin. Int J Pharm 2008;355:269-76.

18. Gursoy RN, Benita S. Self-emulsifying drug delivery systems (SEDDS) for improved oral delivery of lipophilic drugs. Biomed Pharmacother 2004;58;3:173-82.

19. Chouskey R, Pandey H, Jain AK, Soni, H, Saraogi GK. Preparation and evaluation of the self-emulsifying drug delivery system containing atorvastatin HMG-CoA inhibitor. Int J Pharm Pharm Sci 2011;3:147-52.

20. Abdalla A, Mader K. Preparation and characterization of a self- emulsifying pellet formulation. Eur J Pharm Biopharm 2007;66:220-6. 